\title{
Preparation of Tetraheptylammonium Iodide-Iodine Graphite- Multiwall Carbon Nanotube Paste Electrode: Electrocatalytic Determination of Ascorbic Acid in Pharmaceuticals and Foods
}

\author{
Meissam Noroozifar, ${ }^{* \dagger}$ Mozhgan Khorasani-Motlagh, ${ }^{* *}$ and Hamed TavakKoli* \\ *Analytical Research Laboratory, Department of Chemistry, University of Sistan \& Baluchestan, Zahedan, \\ P. O. Box 98155-147, Iran \\ **Inorganic Research Laboratory, Department of Chemistry, University of Sistan \& Baluchestan, Zahedan, Iran
}

\begin{abstract}
The present work describes the construction of a new modified graphite-multiwall carbon nanotube paste electrode by casting the appropriate mixture of tetraheptylammonium iodide-iodine as a new modifier. The modified paste electrode

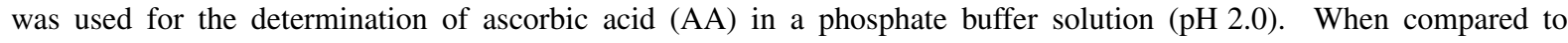
activated carbon, a graphite and multiwall carbon nanotube paste electrode containing a new modifier, the proposed modified paste electrode not only shifted the oxidation potential of AA towards a less-positive potential but also enhanced its oxidation peak current. Further, the oxidation of AA was highly stable at the modified paste electrode. The optimum analytical conditions were sought. The current response of AA increases linearly while increasing its concentration from $5.6 \times 10^{-5}$ to $1.2 \times 10^{-2} \mathrm{M}$ with a correlation coefficient of 0.9991 ; the detection limit $(3 \sigma)$ was found to be of $3.6 \times$ $10^{-5} \mathrm{M}$. The present modified paste electrode was also successfully used for the determination of AA in the presence of common interference compounds. The present modified electrode was successfully demonstrated towards the determination of AA in pharmaceutical and food samples.
\end{abstract}

(Received April 24, 2011; Accepted July 7, 2011; Published September 10, 2011)

Ascorbic acid (AA), a water-soluble compound, is an important micronutrient that, besides its antioxidant effect, is valuable for its vitamin action with playing many physiological roles. During recent years, interest in AA has also increased because of its involvement in the liberation of nitric oxide under various conditions. It can be synthesized by plants and by many mammals, but not by man; it is present in small quantities in food and is indispensable for life, health, and physical and daily activity. ${ }^{1}$ In addition, ascorbate is important for neuronal maturation and function, as well as for protection of the brain against oxidant stress, is well supported by evidence presented in articles. ${ }^{2}$ Therefore, the determination of AA has attracted much attention of researchers. In view of the great importance and wide use of AA, numerous analytical techniques have been proposed for its determination in different matrices and at different levels. These include voltammetry, ${ }^{3-5}$ flow injection (FI) analysis, ${ }^{6-8}$ spectrophotometry, ${ }^{9,10}$ and chromatography. ${ }^{11-13}$ AA can be measured using voltammetry methods in order to gain the advantages of high sensitivity and selectivity. For this purpose, various chemically modified electrodes have been constructed. ${ }^{14-17}$

Carbon nanotubes (CNTs) combine in a unique way high electrical conductivity, high chemical stability and extremely high mechanical strength. These special properties of both single-wall (SW) and multi-wall (MW) CNTs have attracted the interest of many researchers in the field of electrochemical sensors. ${ }^{18}$ Several authors have reported excellent electrocatalytic

$\dagger$ To whom correspondence should be addressed.

E-mail: mnoroozifar@chem.usb.ac.ir properties of nanotubes in the redox behavior of different biomolecules. ${ }^{19}$ The properties of a carbon nanotubes paste electrode (CNTPE) based on the dispersion of CNTs within mineral oil have been demonstrated. ${ }^{19}$

Iodine has been extensively used to flow-injection determinations of numerous organic compounds, such as $\mathrm{AA},{ }^{20}$ adrenaline, ${ }^{21}$ cortisol $^{22}$ and the highly carcinogenic aflatoxins. ${ }^{23}$

Various modifiers have been intensively investigated for the modification of carbon paste electrodes (CPE) for the determination of AA. ${ }^{24-27}$ To the best of our knowledge, no modified electrode, such as CPE using iodine, has been reported concerning the determination of AA.

Farsang studied the redox behavior of the $\mathrm{I}_{2} / \mathrm{I}^{-}$system using a CPE made with silicone oil. ${ }^{28}$ In the present work, the redox system, $\mathrm{I}_{2} / \mathrm{I}^{-}$, was chemically reversible, but electrochemically irreversible, and the slow rate of polarization for the electrogenerated iodine species was attributed to its solubilization into the pasting liquid. Svancara and Konvalina demonstrated a synergistic effect of ion-pairing formation on the extractive preconcentration of iodide as iodine onto a carbon paste surface by using tricresyl phosphate as a pasting liquid. ${ }^{29}$

The present investigation studied the determination of AA at CPEs using tetraheptylammonium iodide-iodine (THAI- $\mathrm{I}_{2}$ ) as a new redox system. As a long-chain tetraalkylammonium salt, THAI can be strongly adsorbed onto a CPE and formed an ion-pair compound with some anions, such as $\mathrm{I}^{-}$and $\mathrm{I}_{3}{ }^{-}$. This reagent with high molecular weight, $537.70 \mathrm{~g} \mathrm{~mol}^{-1}$ is stable under normal temperatures and pressures and slightly soluble in aqueous solution. So, it is a very good casting agent. There is no any report for application of THAI (Fig. 1) for 


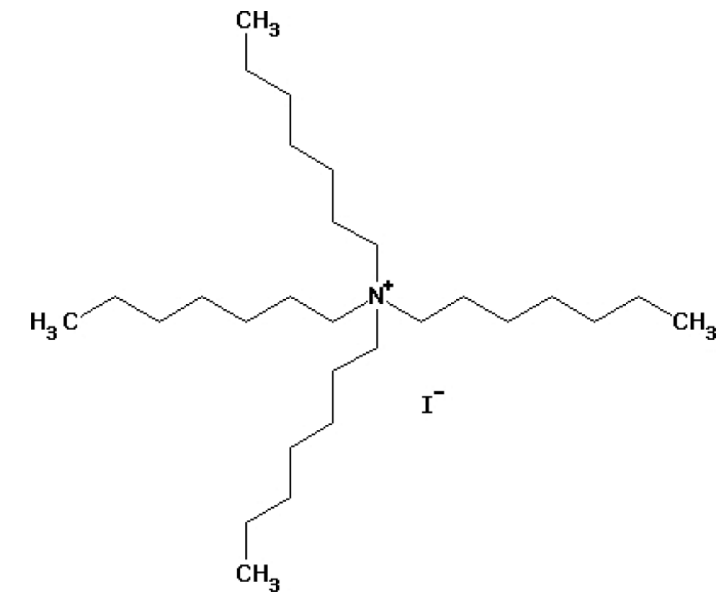

Fig. 1 Chemical structure of tetraheptylammonium iodide.

electroanalytical determinations in literature. THAI is safe and available as a commercial chemical compounds. This paper describes for the first time the details of the development of $\mathrm{THAI} / \mathrm{I}_{2}$ redox system as a new modifier in various paste electrodes such as activated carbon, graphite, multiwall carbon nanotube and a mixture of graphite-multiwall carbon nanotube for electrocatalytic oxidation of AA. The practical application of the modified PE was demonstrated by measuring the concentration of AA in some real and pharmaceutical samples.

\section{Experimental}

\section{Reagents and materials}

Tetraheptylammonium iodide (THAI), iodine $\left(\mathrm{I}_{2}\right)$, activated carbon (AC), graphite fine powder $(\mathrm{G})$, paraffin oil and lithium sulfate (as supporting electrolyte) were obtained from Merck company. Ascorbic acid (AA) was purchased from Fluka-Sigma, and was used as received. Multiwall carbon nanotubes (MWCNT) with nanotube diameters (o.d., $20-30 \mathrm{~nm}$; wall thickness, $1-2 \mathrm{~nm}$; length, $0.5-2 \mu \mathrm{m}$ ) and purity of $>95 \%$ was purchased from Aldrich. Other chemical compounds, such as $\mathrm{H}_{3} \mathrm{PO}_{4}, \mathrm{NaH}_{2} \mathrm{PO}_{4}$ and $\mathrm{NaOH}$, were purchased from Merck. Phosphate buffer solutions (PBS) were prepared from $\mathrm{H}_{3} \mathrm{PO}_{4}$ and $\mathrm{NaH}_{2} \mathrm{PO}_{4}\left(0.1 \mathrm{~mol} \mathrm{~L}^{-1}\right)$, adjusted the $\mathrm{pH}$ range over 2.0 - 10.0 with $0.1 \mathrm{~mol} \mathrm{~L}^{-1} \mathrm{H}_{3} \mathrm{PO}_{4}$ and $\mathrm{NaOH}$ solutions, and were used as supporting electrolytes. All solutions were prepared using doubly distilled water (DDW). The electrolyte solutions were deoxygenated with a nitrogen bubbling before each voltammetric experiment. All experiments were performed under nitrogen atmosphere at room temperature. All solutions were freshly prepared with DDW, and all other chemicals used were of analytical reagent grade.

\section{Instrumentation}

Electrochemical measurements were carried out with an SAMA500 electroanalyzer (SAMA Research Center, Iran) controlled by a personal computer. All electrochemical experiments were carried out in a conventional three-electrode cell at room temperature. A platinum electrode and a saturated calomel electrode (SCE) were used as counter and reference electrodes, respectively. A Metrohm $632 \mathrm{pH}$-meter with a Metrohm double junction glass electrode was used for monitoring any $\mathrm{pH}$ adjustment.

\section{Preparation of working electrodes}

To eliminate metal and metal oxide catalysts within the nanotubes, a 0.2-g amount of MWCNT was dispersed in $60 \mathrm{ml}$ of $4.0 \mathrm{M} \mathrm{HCl}$ for $4 \mathrm{~h}$ with the aid of ultrasonic agitation, rinsed thoroughly with distilled water to neutrality and finally dried. A 0.05 -g amount of MWNT was dispersed in a 60-ml mixture of concentrated $\mathrm{HNO}_{3}$ and $\mathrm{H}_{2} \mathrm{SO}_{4}(1: 3 \mathrm{v} / \mathrm{v})$ with the aid of ultrasonic agitation for $4 \mathrm{~h}$ in a water bath, then washed with distilled water to neutrality and dried.

A mixture of $1.0 \%(\mathrm{w} / \mathrm{w})$ THAI and $1.7 \%(\mathrm{w} / \mathrm{w}) \mathrm{I}_{2}$ spiked AC or G or MWCNT or G-MWCNT was made by dissolving the given quantity of THAI and $\mathrm{I}_{2}$ in ethanol and hand mixing with 99-times its weight of AC or G or MWCNT or a mixture of G-MWCNT (3:1) with a mortar and pestle. The solvent was evaporated by stirring. A 2:1 mixture from the above resulting mixture and paraffin was blended by hand-mixing and the resulting paste was then inserted in the bottom of a polypropylene tube. Electrical connection was implemented by a copper wire lead fitted into the polypropylene tube. The electrodes are denoted as AC/THAI-I ${ }_{2} \mathrm{PE}$, G/THAI- ${ }_{2} \mathrm{PE}$, MWCNT/THAI- $\mathrm{I}_{2} \mathrm{PE}$ and G-MWCNT/THAI- $\mathrm{I}_{2} \mathrm{PE}$. Also, the CPE with $1.0 \%$ (w/w) THAI or $1.7 \%(w / w) I_{2}$ was prepared by same method. A CPE without THAI- $\mathrm{I}_{2}$ was used as a blank to determine the background current. When not in use, the modified electrode was stored in DDW.

\section{Results and Discussion}

\section{The electrochemical study of different PEs}

The electrochemical behavior of a THAI, I $\mathrm{I}_{2}$ and THAI- $\mathrm{I}_{2}$ couple was studied at the surface of different $\mathrm{CPE}$ with $\mathrm{AC}$ by cyclic voltammetry over a potential range from 0.1 to $1 \mathrm{~V}$. Figures $2 \mathrm{a}$ and $2 \mathrm{~b}$ show cyclic voltammograms of two CPEs which contain THAI (AC/THAIPE) and $\mathrm{I}_{2} \quad\left(\mathrm{AC} / \mathrm{I}_{2} \mathrm{PE}\right)$, respectively. As shown in Fig. 2a, there are no anodic and cathodic peaks. Figure $2 \mathrm{~b}$ shows cyclic voltammograms of $\mathrm{AC} / \mathrm{I}_{2} \mathrm{PE}$ in 5 consecutive potential-scan cycles. As shown in Fig. $2 b$, the anodic peak currents decrease with increasing potential scan rates; such results could prove the instability of the modified electrode. Figure $2 \mathrm{c}$ shows cyclic voltammograms of $\mathrm{AC} / \mathrm{THAI}-\mathrm{I}_{2} \mathrm{PE}$ in 5 consecutive potential-scan cycles. Figure $2 \mathrm{c}$ shows a slight change in the anodic peak potential observed after the first potential scan cycle from 0.50 to $0.52 \mathrm{~V}$; then, the anodic peak potential is constant for 4 potential-scan cycles at about $0.52 \mathrm{~V}$. Also, as shown in Fig. 2c, a slight change in the anodic peak currents was observed; such results could prove the stability of the modified electrode. As shown in Fig. 2c, in a positive scan, an oxidation peak was obtained at about $0.52 \mathrm{~V}$, corresponding to the oxidation of iodide to iodine; at a reversal scan no reduction peak was observed. Based on a Farsang report $^{28}$ the redox system, $\mathrm{I}_{2} / \mathrm{I}^{-}$, was chemically reversible, but electrochemically irreversible, and the slow rate of polarization for the electrogenerated iodine species was attributed to solubilization into a pasting liquid, such as silicone oil. Also, when THAI was added, we presumed that both iodide ions $\left(\mathrm{I}^{-}\right)$and iodine $\left(\mathrm{I}_{3}^{-}\right)$may partly from ion-pairs with tetraheptylammonium cations $\left(\mathrm{THA}^{+}\right)$, and are adsorbed on the electrode surface because of the strong affinity of lipophlic carbon paste for THAI. By comparisons of Figs. $2 a, 2 b$ and $2 c$, the affinity of $\mathrm{I}_{3}{ }^{-}$towards $\mathrm{THA}^{+}$may be much stronger than $\mathrm{I}^{-}$ towards it.

The electrochemical behavior of AA $\left(\mathrm{p} K_{\mathrm{a} 1}=4.17, \mathrm{p} K_{\mathrm{a} 2}=\right.$ 11.5 ) is dependent on the $\mathrm{pH}$ value of the aqueous solution. Therefore, $\mathrm{pH}$ optimization of the solution seems to be necessary 

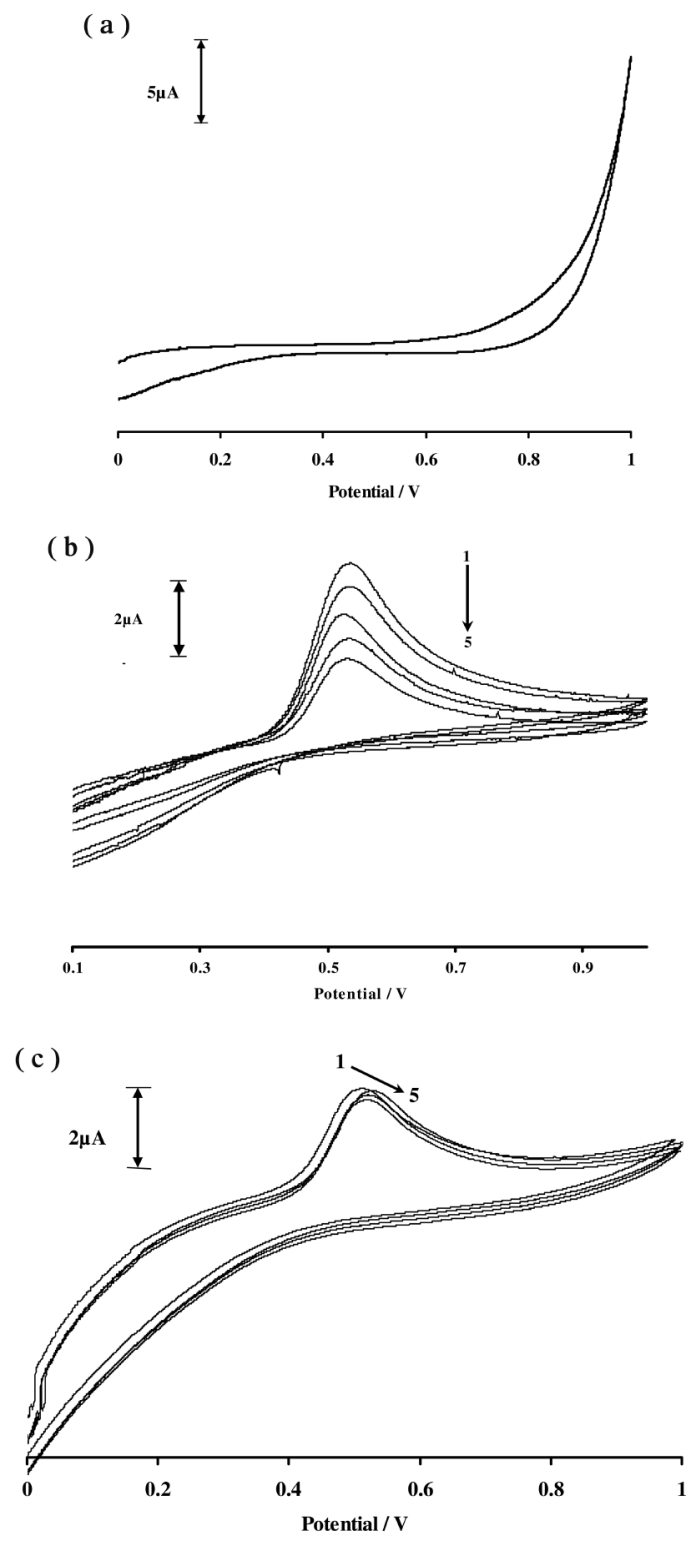

Fig. 2 Cyclic voltammograms of modified paste electrodes. (a) AC/THAIPE. (b) AC/I $2 \mathrm{PE}$ in 5 consecutive potential scan cycles (c) AC/THAI- $\mathrm{I}_{2} \mathrm{PE}$ in 5 consecutive potential scan cycles in $0.1 \mathrm{M}$ PBS (pH 2.0) at $100 \mathrm{mV} \mathrm{s}^{-1}$.

in order to obtain the electrocatalytic oxidation of AA. The effect of the $\mathrm{pH}$ on the anodic peak potential and the peak current of AA was investigated using cyclic voltammetry. The influence of the solution $\mathrm{pH}$ (using PBS buffer) on the peak potential and the current responses of $\mathrm{AA}$ at $\mathrm{AC} / \mathrm{THAI}-\mathrm{I}_{2} \mathrm{PE}$ is shown in Fig. 3a. The variations of anodic peak potential and anodic peak current with respect to the change in the $\mathrm{pH}$ of the electrolyte in the $\mathrm{pH}$ range from 2.0 to 10.0 are shown in Fig. 3b. The results confirm that the peak currents of AA decreased with increasing buffer solution $\mathrm{pH}$ from 2.0 to 7.0, and then increasing with increasing $\mathrm{pH}$ up to about 10.0. Also, the anodic peak potentials increased with increasing $\mathrm{pH}$ from 2.0 to 10.0. It is well known that $\mathrm{AA}\left(\mathrm{p} K_{\mathrm{a} 1}=4.17\right)$ exists as a neutral form at $\mathrm{pH}$ 2.0. Thus, $\mathrm{pH} 2.0$ was chosen as being optimum.

Figure 4 shows cyclic voltammograms over a potential range from 0.0 to $1.0 \mathrm{~V}$, which is related to different $\mathrm{CPE}$ with $\mathrm{AC}, \mathrm{G}$,
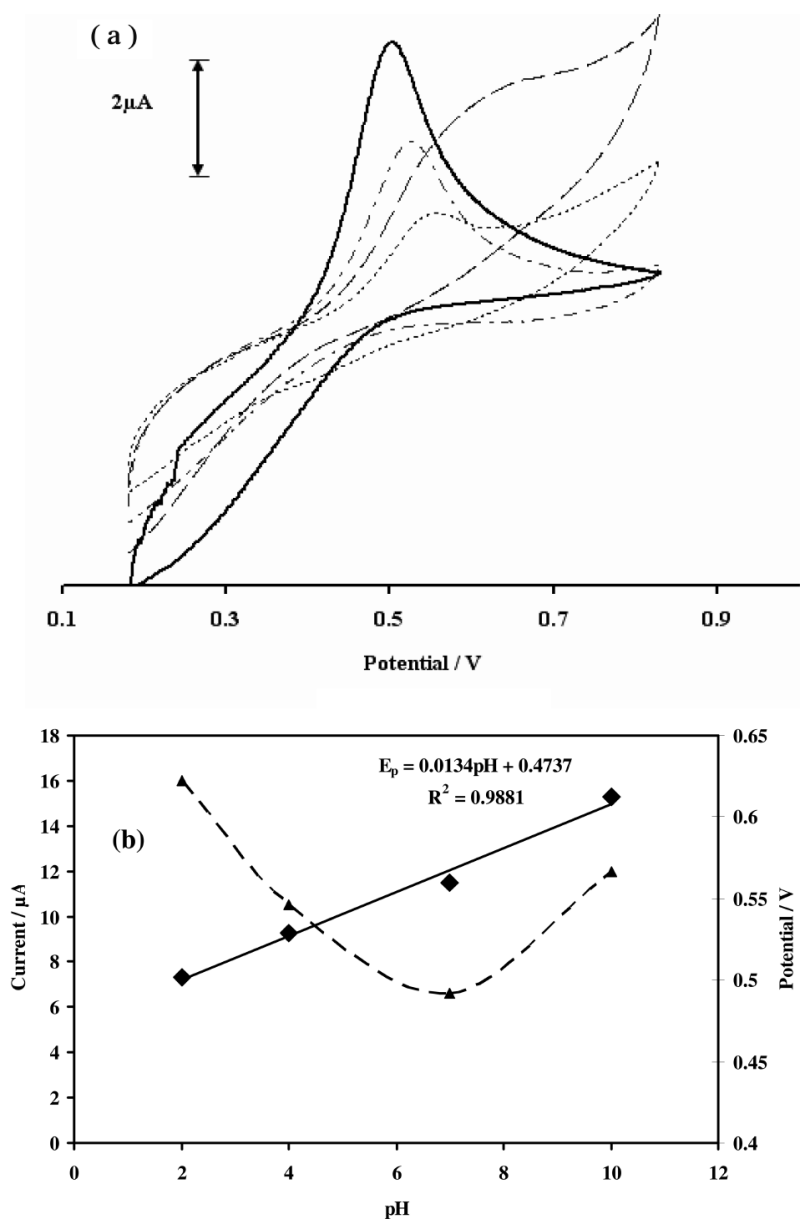

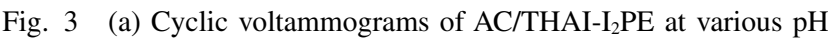
values of 2.0 (solid bold line), 4.0 (dashed dot line), 7.0 (dotted line) and 10.0 (dashed line). b) The effect of $\mathrm{pH}$ on the anodic peak current (solid line) and the anodic peak potential (dashed line) of AC/THAI- $\mathrm{I}_{2} \mathrm{PE}$ at a scan rate of $100 \mathrm{mV} \mathrm{s}^{-1}$.

G-MWCNT and without carbon. In a positive scan, an oxidation peak was obtained at about $0.48 \mathrm{~V}$ for $\mathrm{G} / \mathrm{THAI}-\mathrm{I}_{2} \mathrm{PE}$, corresponding to the oxidation of iodide to iodine $\left(\mathrm{I}^{-} / \mathrm{I}_{3}{ }^{-}\right)$. Also, at a reversal scan, no reduction peak of iodine to iodide $\left(\mathrm{I}_{3}{ }^{-} / \mathrm{I}^{-}\right)$ was observed. Under the same condition, an oxidation peak was obtained at about $0.45 \mathrm{~V}$ for G-MWCNT/THAI- $\mathrm{I}_{2} \mathrm{PE}$, corresponding to the oxidation of iodide to iodine $\left(\mathrm{I}^{-} / \mathrm{I}_{3}{ }^{-}\right)$; also, at a reversal scan, a reduction peak of iodine that formed in the previous scan occurred at nearly $0.26 \mathrm{~V}$. A summary of electrochemical data for the CPEs is given in Table 1. Based on a cyclic voltammogram for G-MWCNT/THAI- ${ }_{2}$ PE (Fig. 4, dashed dotted dot line), the potential of the anodic $\left(E_{\mathrm{pa}}\right)$ and cathodic $\left(E_{\mathrm{pc}}\right)$ peaks and the half-wave potential $\left(E_{1 / 2}\right)$ are 0.451 , 0.264 and $0.358 \mathrm{~V}$, respectively. Also, the peak separation potential, $\Delta E_{\mathrm{p}}\left(\Delta E_{\mathrm{p}}=E_{\mathrm{pa}}-E_{\mathrm{pc}}=0.187 \mathrm{~V}\right)$, is greater than the $0.059 / n \mathrm{~V}$ expected for a reversible system; this result suggests that the $\mathrm{I}^{-} / \mathrm{I}_{3}{ }^{-}$couple does not act as a reversible system in the G-MWCNT/THAI-I $\mathrm{I}_{2} \mathrm{PE}$ matrix, and indicates the quasi-reversible monoelectronic charge-transfer process of the $\mathrm{I}^{-} / \mathrm{I}_{3}^{-}$couple at paraffin oil-based CPEs. The corresponding reactions of these voltammograms:

$3 \mathrm{I}^{-} \rightleftharpoons \mathrm{I}_{3^{-}}+2 \mathrm{e}^{-}$

Equation (1) includes oxidation of the iodide ion $\left(\mathrm{I}^{-}\right)$and 


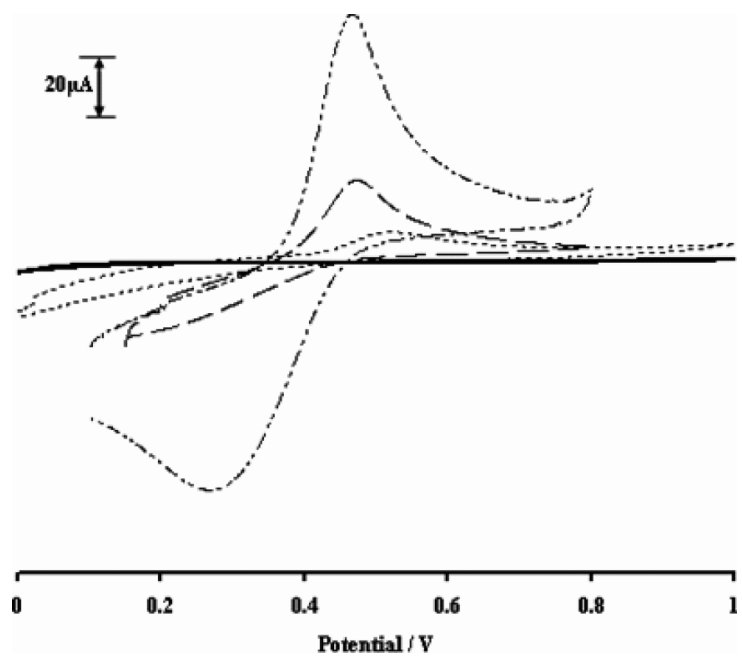

Fig. 4 Cyclic voltammograms of ACPE (solid bold line), AC/THAI- $I_{2} \mathrm{PE}$ (doted line), G/THAI- $\mathrm{I}_{2} \mathrm{PE}$ (dashed line) and G-MWCNT/THAI- $\mathrm{I}_{2} \mathrm{PE}$ (dashed dotted dot line), in PBS with $\mathrm{pH} 2.0$ at a scan rate of $50 \mathrm{mV} \mathrm{s}^{-1}$ (GCPE and G-MWCNTPE are the same as ACPE, and are not shown in figure).

Table 1 Electrochemical data for different PEs $(v s . \text { SCE })^{\mathrm{a}}$

\begin{tabular}{|c|c|c|c|c|c|}
\hline $\begin{array}{l}\text { Electrode } \\
\text { type }\end{array}$ & $\begin{array}{l}E_{\mathrm{pa}} / \\
\mathrm{mV}\end{array}$ & $\begin{array}{l}E_{\mathrm{pc}} l \\
\mathrm{mV}\end{array}$ & $\begin{array}{l}E_{1 / 2} / \\
\mathrm{mV}\end{array}$ & $\begin{array}{l}\Delta E_{\mathrm{p}} / \\
\mathrm{mV}\end{array}$ & $\begin{array}{l}\text { System } \\
\text { type }\end{array}$ \\
\hline $\mathrm{AC} / \mathrm{THAI}-\mathrm{I}_{2} \mathrm{PE}$ & 0.525 & - & - & - & Irreversible \\
\hline G/THAI- $\mathrm{I}_{2} \mathrm{PE}$ & 0.480 & - & - & - & Irreversible \\
\hline $\begin{array}{c}\text { G-MWCNT/ } \\
\text { THAI-I }{ }_{2} \mathrm{PE}\end{array}$ & 0.451 & 0.264 & 0.358 & 0.187 & $\begin{array}{l}\text { Quasi- } \\
\text { reversible }\end{array}$ \\
\hline
\end{tabular}

a. Scan rate, $v=10 \mathrm{mV} \mathrm{s}^{-1} ; \mathrm{pH}, 2.0$.

reduction of the iodine ion $\left(\mathrm{I}_{3}{ }^{-}\right)$with a loss of two electrons in an anodic sweep.

The effect of the scan rate for G-MWCNT/THAI- $\mathrm{I}_{2} \mathrm{PE}$ by using cyclic voltammetry is shown in Fig. 5. These cyclic voltammograms were used to examine the variation of the peak current versus the sweep rate. Figure 5 shows that the modified electrode had a chemically quasi-reversible redox couple in a PBS ( $\mathrm{pH} 2.0$ ) solution, and that peak currents were increased due to the cyclic voltammetric scan rate. As shown in Fig. 5 (inset), $I_{\mathrm{pa}}$ and $I_{\mathrm{pc}}$ were linearly dependent on the scan rate, as expected for a surface confined-redox process. These behaviors are consistent with a diffusionless system, a reversible electron-transfer process at low scan rates. ${ }^{30}$ It has been suggested that the modified electrode reaction could be a two electron transfer process $(n=2)$. An approximate amount of the electroactive species can be estimated by the method suggested by Sharp et al. ${ }^{31}$ for G-MWCNT/THAI- $\mathrm{I}_{2} \mathrm{PE}$. According to this method, the peak current is related to the surface concentration of electroactive species, $\Gamma$, following

$$
I_{\mathrm{p}}=\frac{n^{2} F^{2} A \Gamma V}{4 R T}
$$

Hence $n$ represents the number of electrons involved in the reaction, $A$ is the geometric surface area $\left(0.0314 \mathrm{~cm}^{2}\right)$ of the electrode, $\left.\Gamma(\mathrm{mol} \mathrm{cm})^{-2}\right)$ is the surface coverage, $v$ is the scan rate, $R\left(8.314 \mathrm{~J} \mathrm{~mol}^{-1} \mathrm{~K}^{-1}\right), F\left(96485 \mathrm{C} \mathrm{mol}^{-1}\right)$ and $T(298 \mathrm{~K})$ denote as usual the gas constant, Faraday constant, and
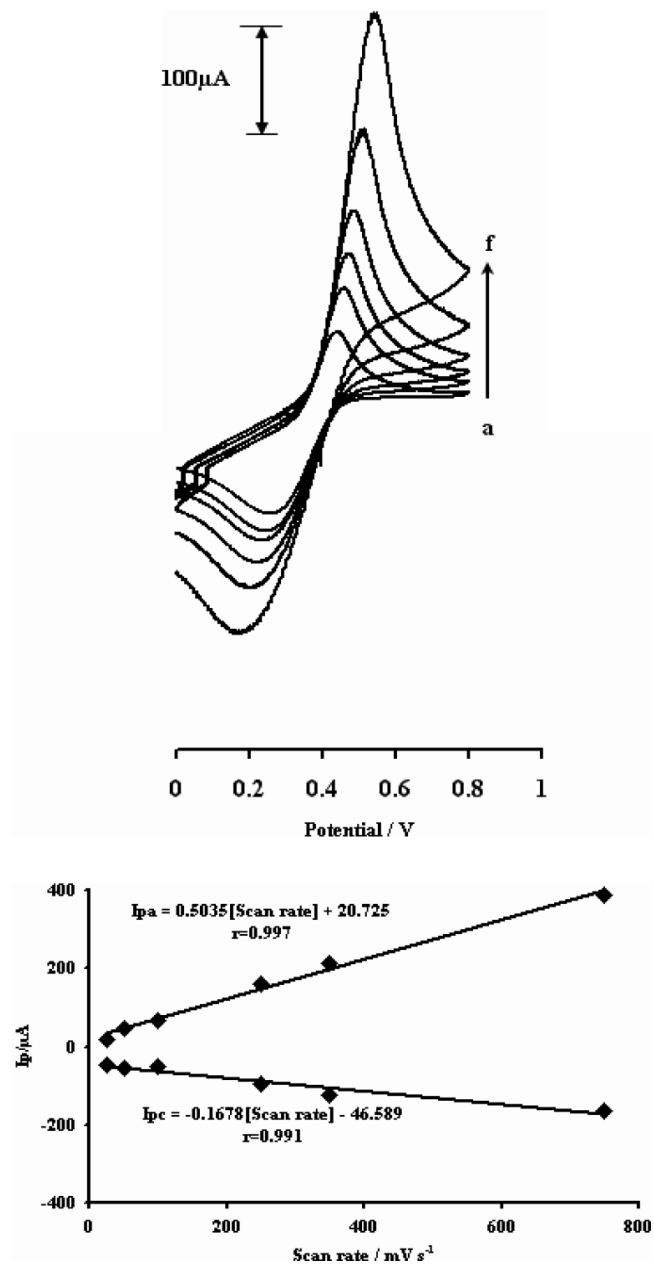

Fig. 5 Cyclic voltammograms of G-MWCNT/THAI- $\mathrm{I}_{2} \mathrm{PE}$ in a $0.1 \mathrm{~mol} \mathrm{~L}^{-1}$ PBS pH 2.0 at various scan rates: (a) 25, (b) 50, (c) 100 , (d) 250 , (e) 350 , (f) $750 \mathrm{mV} \mathrm{s}^{-1}$. Inset: Plots of the anodic and cathodic peak currents of G-MWCNT/THAI- $\mathrm{I}_{2} \mathrm{PE} v s$. scan rate $(v)$ from cyclic voltammograms.

temperature, respectively. From the slope (from Fig. 5, inset) of anodic peak currents versus scan rate, the surface concentration of CMF was calculated to be $4.27 \times 10^{-8} \mathrm{~mol} \mathrm{~cm}^{-2}$ for $n=2$.

\section{Stability and life time of G-MWCNT/THAI-I $I_{2} P E$}

The stability of G-MWCNT/THAI- ${ }_{2} \mathrm{PE}$ was studied by noting the decrease in anodic charge, $q_{\mathrm{a}}$, in repetitive potential scan cycles. The rate of loss of electrochemical activity for the modified electrode was investigated prior to use. Cyclic voltammograms of G-MWCNT/THAI- $\mathrm{I}_{2} \mathrm{PE}$ in consecutive 5 potential-scan cycles in PBS at scan rate of $50 \mathrm{mV} \mathrm{s}^{-1}$ (Fig. 6). Only a little change for anodic and cathodic peak currents has been observed and these results could prove the stability of the modified electrode.

Prior to using the G-MWCNT/THAI- $\mathrm{I}_{2} \mathrm{PE}$ for the electrocatalytic oxidation of AA, the rate of loss of electrochemical activity for this electrode was investigated. This rate was evaluated by noting the decrease in the anodic charge, $q_{\mathrm{a}}$, in consecutive potential-scan cycles. The result showed that the anodic and cathodic peak currents of the $\mathrm{I}^{-} / \mathrm{I}_{3}{ }^{-}$couple decreased; consequently, the electrochemical activity of G-MWCNT/THAI- $\mathrm{I}_{2} \mathrm{PE}$ was reduced during successive scans, without any change in the half-wave potential, $E_{1 / 2}$. The decrease in the electrochemical 
activity may be due to removal of the $\mathrm{I}^{-}$and $\mathrm{I}_{3}{ }^{-}$ions produced at the electrode by dissolution into an aqueous solution. Also, G-MWCNT/THAI- $\mathrm{I}_{2} \mathrm{PE}$ was stable for 2 months. According to

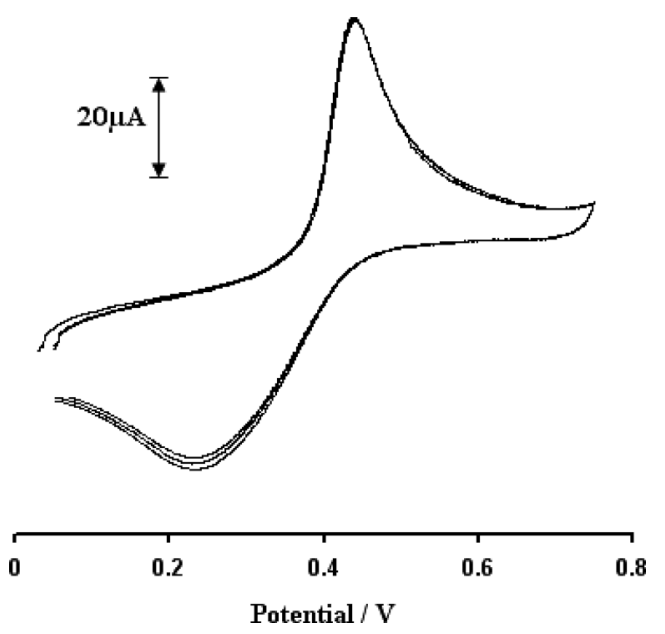

Fig. 6 Cyclic voltammograms of G-MWCNT/THAI- $\mathrm{I}_{2} \mathrm{PE}$ in 5 consecutive potential-scan cycles in PBS ( $\mathrm{pH} 2.0$ ) at a scan rate of $50 \mathrm{mV} \mathrm{s}^{-1}$. the above results, surface regeneration of the G-MWCNT/THAI- $\mathrm{I}_{2} \mathrm{PE}$ before each experiment is necessary.

Electrocatalytic oxidation of AA at the surface of different PEs

The prime objective of the present work is to determine the concentration of AA using a PE modified electrode. Figure 7 shows CVs obtained for different CPE modified electrodes in $0.1 \mathrm{M}$ PBS $\mathrm{pH} 2.0$ containing $0.5 \mathrm{mM}$ AA. The ACPE, AC/THAI- $\mathrm{I}_{2} \mathrm{PE}, \mathrm{G} / \mathrm{THAI}-\mathrm{I}_{2} \mathrm{PE}$ and G-MWCNT/THAI-I $\mathrm{I}_{2} \mathrm{PE}$ electrodes showed an oxidation wave for $6.9 \times 10^{-4} \mathrm{M}$ AA at $660,555,506$ and $470 \mathrm{mV}$ (Fig. 7) and a current difference $(\Delta I / \mu \mathrm{A})$ for $6.9 \times 10^{-4} \mathrm{M}$ AA $5.5,3.5,6.9$ and $56.9 \mu \mathrm{A}$, respectively. On the other hand, when the G-MWCNT/THAI- $\mathrm{I}_{2} \mathrm{PE}$ electrode was compared with the ACPE, AC/THAI- $\mathrm{I}_{2} \mathrm{PE}$, G/THAI- $\mathrm{I}_{2} \mathrm{PE}$ electrodes, the oxidation peak potential of AA was shifted to 190,85 and $36 \mathrm{mV}$ less positive potential. Also, the oxidation current for the G-MWCNT/THAI- $\mathrm{I}_{2} \mathrm{PE}$ electrode was greatly increased in compared with ACPE, AC/THAI- $\mathrm{I}_{2} \mathrm{PE}$, G/THAI-I ${ }_{2} \mathrm{PE}$. The mechanism of this phenomenon can be written as follows:

$$
\begin{aligned}
& 3 \mathrm{I}^{-} \longrightarrow \mathrm{I}_{3^{-}}+2 \mathrm{e}^{-}, \\
& \mathrm{I}_{3}{ }^{-}+\mathrm{AA} \longrightarrow 3 \mathrm{I}^{-}+\mathrm{DHAA}+2 \mathrm{H}^{+} .
\end{aligned}
$$

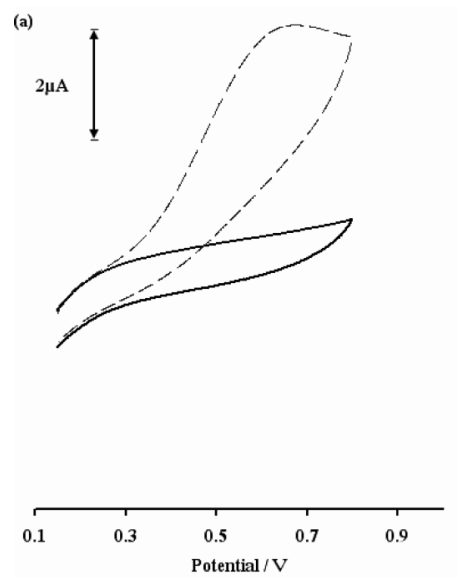

(C)

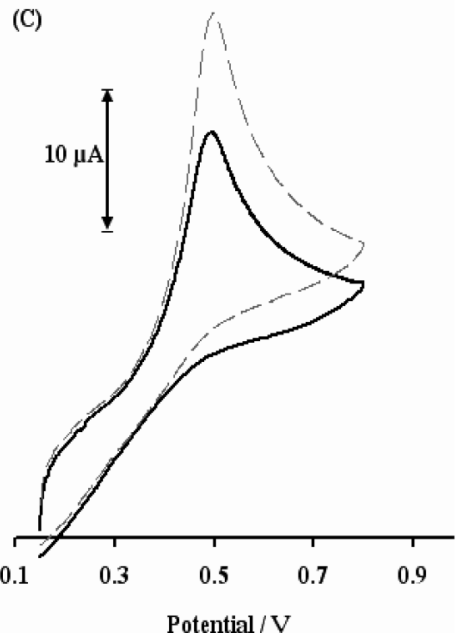

(b)

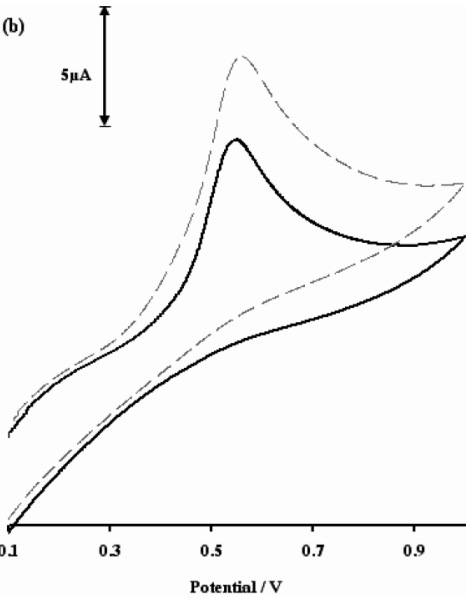

(d)

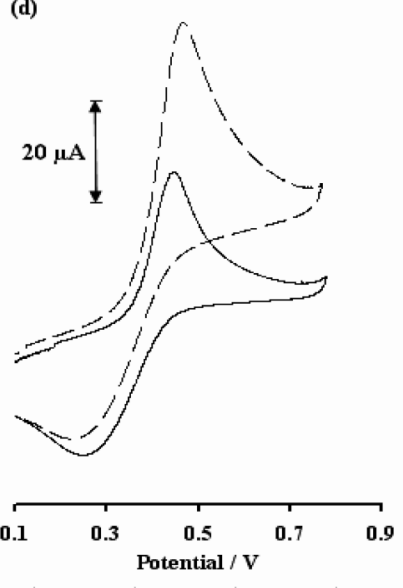

Fig. 7 Cyclic voltammograms of (a) ACPE, (b) AC/THAI- $\mathrm{I}_{2} \mathrm{PE}$, (c) G/THAI- $\mathrm{I}_{2} \mathrm{PE}$ and (d) G-MWCNT/THAI-I $\mathrm{I}_{2} \mathrm{PE}$ in the absence of AA (solid bold line) in the presece of $6.9 \times 10^{-4} \mathrm{M} \mathrm{AA}$ (dashed line) in PBS (pH 2.0) at a scan rate of $50 \mathrm{mV} \mathrm{s}^{-1}$. 
These results showed that the electrooxidation of AA to dehydroascorbic acid (DHAA) can be catalyzed by the $\mathrm{I}^{-} / \mathrm{I}_{3}{ }^{-}$couple as a mediator at the surface of the modified electrode.

In order to obtain the best composition of the G-MWCNT/THAI- $\mathrm{I}_{2} \mathrm{PE}$ electrode, we used different quantities ratios of G:MWCNT = 1:3, 2:2, 3:1, 3.5:0.5 for the preparation of modified electrodes. For this work, with increasing the MWCNT amount (G:MWCNT = 1:3, 2:2), the anodic peak potential for the G-MWCNT/THAI- ${ }_{2}$ PE electrode was shifted to a positive potential, and with decreasing of the MWCNT amount (G:MWCNT = 3.5:0.5) the anodic peak potential for the G-MWCNT/THAI-I ${ }_{2} \mathrm{PE}$ electrode was similar to that of the G/THAI- $\mathrm{I}_{2} \mathrm{PE}$ electrode. According to these results, we selected the optimum composition 3:1 (G:MWCNT) in all experimental work.

To understand the fast electron-transfer reaction of $\mathrm{AA}$ at the G-MWCNT/THAI- $\mathrm{I}_{2} \mathrm{PE}$ modified electrode quantitatively, we calculated the standard heterogeneous rate constant $\left(k_{\mathrm{s}}\right)$ for AA at G-MWCNT/THAI- $\mathrm{I}_{2} \mathrm{PE}$ and bare ACPE electrodes using the Velasco equation, as given below: ${ }^{32}$

$$
k_{\mathrm{s}}=1.11 D_{\mathrm{o}}^{1 / 2}\left(E_{\mathrm{p}}-E_{\mathrm{p} 1 / 2}\right)^{-1 / 2} V^{1 / 2},
$$

where $k_{\mathrm{s}}$ is the standard heterogeneous rate constant; $D_{\mathrm{o}}$ the apparent diffusion coefficient; $E_{\mathrm{p}}$ the oxidation peak potential; $E_{\mathrm{p} 1 / 2}$ the half-wave oxidation peak potential, and $v$ the scan rate. In order to determine $k_{\mathrm{s}}$, it is necessary to find the diffusion coefficient for AA. The apparent diffusion coefficient $\left(D_{\mathrm{o}}\right)$ value was determined by a single potential chronoamperometry technique based on the Cottrell slope obtained by plotting versus $1 / \sqrt{\text { time. }}$. Chronoamperometry measurements were carried out for AA both at bare ACPE and G-MWCNT/THAI- $\mathrm{I}_{2} \mathrm{PE}$ electrodes. Based on the Cottrell equation, the diffusion coefficient of AA was found to be $5.47 \times 10^{-5} \mathrm{~cm}^{2} \mathrm{~s}^{-1}$ for the G-MWCNT/THAI- $\mathrm{I}_{2} \mathrm{PE}$ electrode. ${ }^{33}$ The estimated standard heterogeneous rate constant $\left(k_{\mathrm{s}}\right)$ values for the totally irreversible oxidation of AA both at bare ACPE and G-MWCNT/THAI- $\mathrm{I}_{2} \mathrm{PE}$ electrodes were found to be $1.21 \times 10^{-3}$ and $9.6 \times 10^{-3} \mathrm{~cm} \mathrm{~s}^{-1}$, respectively. The obtained higher $k_{\mathrm{s}}$ value for $\mathrm{AA}$ at the G-MWCNT/THAI- $\mathrm{I}_{2} \mathrm{PE}$ modified electrode indicated that the oxidation of AA was faster at the G-MWCNT/THAI- $\mathrm{I}_{2} \mathrm{PE}$ electrode than at the ACPE electrode.

\section{Evaluation of the proposed modified electrode}

Under the optimum conditions, the determination of AA was carried out at the potential range of 0.1 to $0.9 \mathrm{~V}$ using the cyclic voltammetry mode. The AA electro-oxidation peak was observed at potential of about $0.470 \mathrm{~V}$ versus SCE. The electrocatalytic peak current of $\mathrm{AA}$ at the surface of G-MWCNT/THAI- $\mathrm{I}_{2} \mathrm{PE}$ was linearly dependent on the AA concentration. These peak currents were linear up to $0.012 \mathrm{M}$, described by the equation $\Delta I(\mu \mathrm{A})=36436[\mathrm{AA}]+57.4, r=$ $0.9991, n=12$, where $\Delta I(\mu \mathrm{A})$ is the difference in the oxidation peak currents G-MWCNT/THAI- $\mathrm{I}_{2} \mathrm{PE}$ before and after the addition of AA, [AA] (M) the AA concentration, $r$ the correlation coefficient and $n$ represents the number of determinations (Fig. 8). The detection limit $(3 \sigma)$ was $3.6 \times 10^{-5} \mathrm{M}$. The relative standard deviation (RSD \%) for 5 determinations of AA with $4.6 \times 10^{-4} \mathrm{M}$ concentration was $0.6 \%$.

\section{Interference study}

For investigating interference, several compounds were selected. If the tolerance limit was taken as the maximum concentration of foreign substances, which caused an

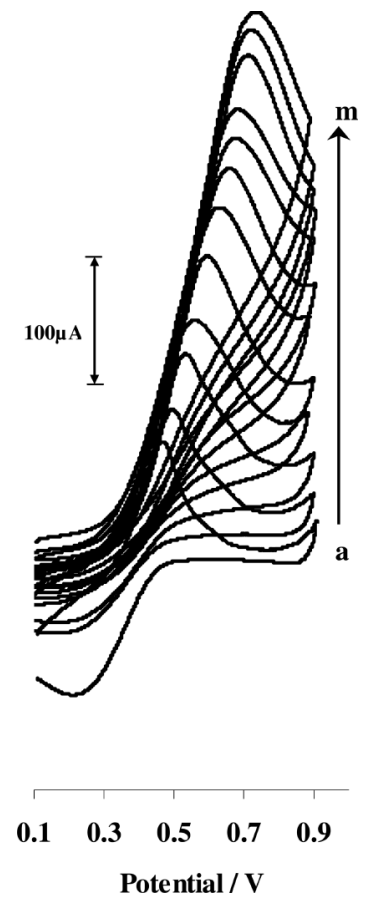

Fig. 8 Cyclic voltammograms of $\mathrm{AA}$ at various concentration (from a to $\mathrm{m}$ ): $0.0,7.8 \times 10^{-5}, 6.5 \times 10^{-4}, 1.4 \times 10^{-3}, 2.2 \times 10^{-3}, 3.4 \times$ $10^{-3}, 4.5 \times 10^{-3}, 5.7 \times 10^{-3}, 7.1 \times 10^{-3}, 8.4 \times 10^{-3}, 1.0 \times 10^{-2}$ and $1.2 \times$ $10^{-2} \mathrm{M}$ at surface of the G-MWCNT/THAI-I ${ }_{2} \mathrm{PE}$. The solution conditions were $\mathrm{pH} 2.00(0.1 \mathrm{M} \mathrm{PBS}+0.1 \mathrm{M} \mathrm{LiCl})$. The scan rate was $100 \mathrm{mV} \mathrm{s}^{-1}$.

approximately $5 \%$ relative error, for $1.2 \times 10^{-4} \mathrm{~mol} \mathrm{~L}^{-1} \mathrm{AA}$, no interference was observed for the following compounds: lactose, maleic acid, glycine, maltose succharose fructose, oxalic acid, succinic acid, tartaric acid and glucose. The results are listed in Table 2.

\section{Application in real samples}

In order to prove the capability of this modified electrode for the catalytic oxidation of AA in the real samples, we examined this ability in the voltammetric determination of AA in some pharmaceutical preparations and foods. Therefore, pharmaceutical tablet solutions were prepared by accurately weighing and grinding of tablets, and then filtering of any dissolved obtained powder in the working buffer solution. The determination of AA in pharmaceutical preparations was carried by the standard addition method in order to prevent on any matrix effect. The results were compared with those obtained using the official iodometric titration method. ${ }^{34}$ The paired $t$-test equation, applied in statistics is

$$
t=\left|\frac{\bar{d} \sqrt{n}}{s_{\mathrm{d}}}\right|,
$$

where $\bar{d}$ and $s_{\mathrm{d}}$ are the mean and standard deviation, respectively, of $\bar{d}$ (the difference between paired values). For the pairs of values given in Table 3 , the mean difference, $\bar{d}$, is -2.275 , and the standard deviation of the differences, $s_{\mathrm{d}}$, is 3.17. The calculated $|t|$ was found to be 1.44. The critical value of $t$ (tabulated $t$ ) for $n-1$ degrees of freedom (in this work 3 ) is $3.18(P=0.05)$. Since the calculated value of $t$ is less than this, the null hypothesis is not rejected; the methods do not give significantly different results for the AA concentration. ${ }^{35}$ 
Table 2 Effect of diverse substances on the analysis of $1.5 \times$ $10^{-3} \mathrm{~mol} \mathrm{~L}^{-1} \mathrm{AA}$

\begin{tabular}{lc}
\hline \multicolumn{1}{c}{ Substance } & $\begin{array}{c}\text { [Interference } \\
\text { substance]/[AA] }\end{array}$ \\
\hline Lactose, maleic acid, glycine, maltose & 1000 \\
Succharose & 500 \\
Fructose & 100 \\
Oxalic acid, succinic acid, tartaric acid & 50 \\
Glucose & 10 \\
\hline
\end{tabular}

Table 3 Determination of AA in real samples with using a G-MW/THAI-I ${ }_{2} \mathrm{PE}$ electrode

\begin{tabular}{lccc}
\hline \multicolumn{1}{c}{ Sample } & $\begin{array}{c}\text { Claimed } \\
\text { preparation/ } \\
\mathrm{mg}\end{array}$ & $\begin{array}{c}\text { Proposed } \\
\text { methoda/ } \\
\mathrm{mg}( \pm \mathrm{SD})\end{array}$ & $\begin{array}{c}\text { Iodine } \\
\text { method }^{\mathrm{a}} / \\
\mathrm{mg}( \pm \mathrm{SD})\end{array}$ \\
\hline AA powder & 500 per sachet & $479.5( \pm 1.6)$ & $483.2( \pm 1.2)$ \\
AA tablet & 250 per tablet & $237.8( \pm 1.8)$ & $242.1( \pm 1.3)$ \\
Egypt's orange & - & $87.1( \pm 1.9)$ & $83.9( \pm 2.0)$ \\
$(100 \mathrm{ml})$ & - & $57.0( \pm 2.4)$ & $61.3( \pm 2.0)$ \\
$\begin{array}{c}\text { Baluchestan's } \\
\text { lemon }(100 \mathrm{ml})\end{array}$ & - & & \\
\hline
\end{tabular}

a. Results based on five replicate determinations per sample.

\section{Conclusions}

The construction of a graphite-multiwall carbon nanotube/ tetraheptylammonium iodide-iodine paste electrode and its use for electrocatalytic oxidation and the determination of different concentrations of AA was described. The overpotential was reduced with a value of $190 \mathrm{mV}$ for the oxidation of AA. The experimental conditions, such as $\mathrm{pH} 2$ of the supporting electrolyte, scan rate of $100 \mathrm{mV} \mathrm{s}^{-1}$ and composition of the G-MWCNT/I $\mathrm{I}_{2}$-THAIPE have been used for the determination of AA. To study the capability of this modified electrode in real samples, some pharmaceutical preparations and foods were used, and compared with the standard titrimetric method. There was no significant difference between the two methods. An simple fabrication procedure, a wide linear range, high stability and good reproducibility for repeated determinations, suggest this electrode being as a good, cheap and an attractive candidate for practical applications.

\section{Acknowledgements}

We gratefully acknowledge financial support from the University of Sistan \& Baluchestan (USB) Research Vice Chancellory (GN. 87g10).

\section{References}

1. A. Garrido Frenich, M. E. Hernaa Ndez Torres, A. Belmonte Vega, J. L. Martianez Vidal, and P. Plaza Bolanos, J. Agric. Food Chem., 2005, 53, 7371.

2. F. E. Harrison and J. M. May, Free Radical Biol. Med., 2009, 46, 727 .

3. M. Khorasani-Motlagh and M. Noroozifar, Anal. Sci., 2003 ,
19, 1671.

4. S. Ashok Kumar, P. H. Lo, and S. M. Chen, Biosens. Bioelectron., 2008, 24, 518.

5. M. Sahin, L. Ozcan, B. Usta, and Y. Sahin, Biosens. Bioelectron., 2009, 24, 3492.

6. O. Gilbert, B. E. Kumara Swamy, U. Chandra, and B. S. Sherigara, J. Electroanal. Chem., 2009, 636, 80.

7. M. Noroozifar and M. Khorasani-Motlagh, Talanta, 2003, 61,173

8. M. Noroozifar, M. Khorasani-Motlagh, and A. R. Farahmand, Acta Chim. Slov., 2004, 51, 717.

9. T. Takayanagi, M. Nishiuchi, M. Ousaka, M. Oshima, and S. Motomizu, Talanta, 2009, 79, 1055.

10. M. O. Zyürek, K. Güclü, B. Bektas, and O. Apak, Anal. Chim. Acta, 2007, 588, 88 .

11. G. Burini, J. Chromatogr., A, 2007, 1154, 97.

12. L. Wang, L. Zhang, S. She, and F. Gao, Spectrochim. Acta, Part A, 2005, 61, 2737.

13. X. Li and A. A. Franke, J. Chromatogr., B, 2009, 877, 853.

14. A. Sivanesan, P. Kannan, and S. Abraham John, Electrochim. Acta, 2007, 52, 8118.

15. J.-B. Raoof, R. Ojani, R. Hosseinzadeh, and V. Ghasemi, Anal. Sci., 2003, 19, 1251.

16. R. Takita, K. Yoshida, and J. I. Anzai, Sens. Actuators, B, 2007, 121, 54

17. T. Rohani and M. A. Taher, Talanta, 2009, 78, 743.

18. A. Merkoci, M. Pumera, X. Llopis, B. Pérez, M. del Valle, and S. Alegret, Trends Anal. Chem., 2005, 24, 826.

19. M. D. Rubianes and G. A. Rivas, Electrochem. Commun. 2003, 5, 689

20. M. Noroozifar and M. Khorasani-Motlagh, Talanta, 2003 , 61,173

21. A. Kojo and J. Martínez Calatayud, Anal. Chim. Acta, 1995, 308, 334.

22. M. Carlton, M. Hasler, and K. Painter, Radiochem Radioanal. Lett., 1979, 39, 19.

23. H. Jansen, R. Jansen, U. A. T. Brinkman, and R. W. Frei, Chromatographia, 1987, 24, 555.

24. J.-B. Raoof, R. Ojani, and S. Rashid-Nadimi, Electrochim. Acta, 2004, 49, 271

25. R. Akbari, M. Noroozifar, M. Khorasani-Motlagh, and A. Taheri, Anal. Sci., 2010, 26, 425.

26. B. Nalini and S. S. Narayanan, Anal. Chim. Acta, 2000, 405, 93.

27. Z. Guorong, W. Xiaolei, S. Xingwang, and S. Tianling, Talanta, 2000, 51, 1019.

28. G. Farsang, Acta Chim. Hung., 1965, 45, 163

29. I. Svancara and J. Konvalina, Electroanalysis, 1998, 10, 787.

30. L. Fernández and H. Carrero, Electrochim. Acta, 2005, 50, 1233.

31. M. Sharp, M. Petersson, and K. Edstrom, J. Electroanal. Chem., 1979, 95, 123

32. J. G. Velasco, Electroanalysis, 1997, 9, 880.

33. A. J. Bard and L. R. Faulkner, "Electrochemical 455 Methods: Fundamentals and Applications", 2nd ed., 2001, John Wiley, New York.

34. A. A. Izuagie and F. O. Izuagie, J. Agric. Biol. Sci., 2007, $3,367$.

35. J. C. Miller and J. N. Miller, "Statistics for Analytical Chemistry", 2nd ed., 1988, John Wiley and Sons, New York, 58. 